\title{
VALIDITY AND RELIABILITY OF TURKISH VERSION OF BELIEFS ABOUT THIRD-HAND SMOKE SCALE: BATHS-T
}

\author{
Dursun Çadırcı', Nuray Kıvanç Terzi ${ }^{1}$, Ragıp Terzi ${ }^{2}$, Fatma Gökşin Cihan ${ }^{3}$ \\ ${ }^{1}$ Family Medicine Department, Medical Faculty, Harran University, Sanliurfa, Turkey \\ ${ }^{2}$ Educational Measurement and Evaluation Department, School of Education, Harran University, Sanliurfa, Turkey \\ ${ }^{3}$ Family Medicine Department, Meram Medical Faculty, Necmettin Erbakan University, Konya, Turkey
}

\section{SUMMARY}

Objective: Exposure to third-hand smoke (THS) poses health risk, especially for children. THS is mostly ignored in Turkey. The aim of this study is to adapt the Beliefs about Third-Hand Smoke (BATHS) scale to Turkish.

Methods: The BATHS scale consists of 9 items, and the data collected from 273 people was considered sufficient for analyses in this methodological study. The BATHS scale is translated into Turkish and confirmatory factor analysis (CFA) was performed for the construct validity analysis of the scale.

Results: The correlation between the overall BATHS scale and its two sub-dimensions was $0.937(p<0.001)$, and the correlation between the health and persistence sub-dimensions was $0.775(p<0.001)$. Since there was a statistically positive and highly significant relationship, the adapted BATHS scale was considered structurally compatible with the sub-dimensions. The reliability value of the entire scale is 0.90 . Test-retest correlation values between the health and persistence dimensions were between 0.745 and 0.960 , the values obtained were above 0.70 and had a statistically positive and high level of significant relationship $(p<0.001)$.

Conclusions: It is concluded that the Turkish version of the BATHS scale is reliable and valid. This scale will allow further research and training on third-hand smoke exposure. Tobacco control programmes success will improve.

Key words: beliefs, environmental tobacco smoke pollution, passive smoking, reliability and validity, smoking prevention

Address for correspondence: D. Çadırcı, Harran University, Faculty of Medicine, Family Medicine Department, Sanliurfa, Turkey. E-mail: drdcadirci@harran.edu.tr

https://doi.org/10.21101/cejph.a6578

\section{INTRODUCTION}

Smoking is still an important public health problem in Turkey and all over the world (1). Tobacco use is among the top causes of death, and despite the efforts of governments and health institutions worldwide and dozens of precautions taken, problems cannot be prevented (2). Smokers continue to be a serious health threat for not only themselves but also non-smokers.

The ban on smoking was first implemented in San Luis Obispo, California, in 1990, including bars and restaurants in all public indoor spaces. In the following years, this practice has spread into many countries. One of the most important reasons is that the harmful effects of smoking are not limited to smokers, and smoke is shared with non-smokers who are in the same indoor areas (2, 3). Clear scientific evidence has emerged that the resulting passive smoking (second-hand smoke) is very dangerous (2-4).

The term third-hand smoke (THS) is a relatively new concept. This term, which was used for the first time in 2006, was reintroduced by Winickoff et al. in 2009 (5), but it showed its main effects after the New York Times published its article on this subject $(6,7)$. Third-hand smoke has a lower concentration than second-hand smoke, but it causes longer exposure (8). Exposure to second-hand cigarette smoke is a result of involuntary inhalation of the smoke combination released from the cigarette and released into the environment (4). Third-hand smoke exposure is caused by dust and surfaces, inhalation, ingestion (digestion), and dermal intake of cigarette residues in addition to air $(9,10)$. Dermal absorption is another important way of exposure to pollutants bound to settled dust (9).

Several studies have considered THS as an unexpected public health hazard (2). THS is divided into ultra-small pieces after smoking tobacco. These parts are capable of undergoing chemical transformation (9). These parts, which remain on the surfaces and mix with the powders, can then go back into the gas phase, and react with other compounds in the environment to produce carcinogenic substances that are repeatedly inhaled (1).

Although restrictions in public spaces are promising, these prohibitions can make home environments the main source of passive smoking $(1,3)$. Therefore, the study conducted in the United States in 2006 shows that the effect of these prohibitions on protecting young children is much slower than in adults (3). As studies deepen, there is evidence that exposure to THS poses health risk, especially for children (2). Babies have twice as much contact with house dust than adults. Therefore, they are 
more exposed to dust particles mixed with powder (40 times their body weight compared to adults) $(9,11)$. In addition, babies have a higher rate of hand-object-mouth contact, which causes more carcinogenic entry into the body through both inhalation and contacts. Taking into account the immature respiratory and immune systems, the picture can get even more serious $(9,12,13)$.

Related studies have shown that smoking indoors for only one day exposes people to tobacco toxins for days or even months $(9$, $13,14)$. THS, which accumulated in the smokers' houses, was able to maintain its permanence even after these houses were left empty for 2 months and then cleaned $(15,16)$. Studies suggest that people who have moved to a new house may be exposed to the harmful effects of smoking even if they do not smoke $(15,17)$.

The study conducted in Atlanta in 2013 revealed that there is an unknown danger due to THS. In this study investigating the level of consciousness of THS, it was observed that almost all participants did not hear anything about THS and did not know what the term meant (17). In the research conducted by Winickoff et al., it was concluded that there was no awareness of the exposure in children (5). In another study related to THS beliefs, it was observed that the parents who did not believe in THS effects initially attempted to quit smoking after gaining knowledge about THS (18). This information shows that having accurate information about THS and its harms can contribute to creating a smoke-free environment (18-20). However, there are still very few studies examining the consciousness level of THS.

In light of this literature, it is thought that the Beliefs about Third-Hand Smoke (BATHS) scale can more accurately evaluate the belief in the harmful effects of THS and this evaluation may be effective in smoking cessation (20). The main purpose of this study is to adapt the BATHS scale into Turkish and to examine its validity and reliability. Based on the data collected from this scale adapted to Turkish, it is aimed to examine the differences in beliefs based on the socio-demographic characteristics of the participants.

\section{MATERIALS AND METHODS}

Ethical approval for this study was obtained from the Ethics Committee of Harran University Medical Faculty on 7 January 2019 with number 19.01.28.

\section{Participants}

The sample of this methodological study consisted of people registered in family healthcare centres in Şanlıurfa. This study aimed to adapt the THS scale to Turkish, and since there was no generalization for the entire universe, participants were selected with the convenience sampling technique. In factor analysis, the sample size is recommended to be around 10 times the number of items $(21,22)$. The BATHS scale consists of 9 items, and the data collected from 273 people was considered sufficient for the analyses.

\section{Adaptation of BATHS Scale to Turkish}

Given the purpose of this study, the BATHS with 9 items, which is two-dimensional (health and persistence) as in the original, has a 5-point Likert-type scoring ( 1 - strongly disagree, 2 - disagree, 3 - undecided, 4 - agree, 5 - strongly agree). Firstly, three academicians whose second language is English translated the scale from English to Turkish. The consistency of these translations was analysed and reconciled. The Turkish version of the BATHS scale was then back translated into English by another academician and was compared with the original one.

Furthermore, confirmatory actor analysis (CFA) was performed using the MPlus 7.0 version for the construct validity analysis of this final Turkish scale (23). In addition to the construct validity examined by CFA, the correlation between the sub-dimensions of the entire scale was examined for the criterion validity. The reliability coefficients of all scales and dimensions in terms of internal consistency were then calculated by the Cronbach's alpha method for reliability analysis using Statistical Package for Social Sciences (IBM SPSS) 22.0 version. In addition to the Cronbach's alpha method, reliability analysis was performed using the test-retest method.

\section{Demographic Variable Analysis According to THS Scale}

Using the BATHS scale, the data collected from 273 participants were examined according to socio-demographic variables. Although the score of the whole scale can be calculated according to the average of the items, since it is statistically more accurate in this study, the relevant dimension of each item was calculated by standardizing it with the weighted mean method based on the degree of explanation (i.e. item quality). Therefore, when interpreting point averages, it should be interpreted as standardized score (z-score) instead of 5-point (5-point Likert scale). For the purposes of the researcher, the score obtained from the BATHS scale (continuous variable) was the dependent variable, and the socio-demographic characteristics (categorical variable) of the participants are considered as independent variables, and whether the beliefs of the participants about third-hand smoke have changed according to the independent variables was examined. Because of the fact that socio-demographic variables consist of two groups, independent sample t-test was carried out. Moreover, in cases where independent variables consisting of more than two categorical groups one-way analysis of variance (ANOVA) was carried out. Since these analyses are based on parametric tests, parametric test assumptions were examined.

\section{RESULTS}

The socio-demographic characteristics of the participants are given in Table 1.

\section{Confirmatory Factor Analysis}

For the construct validity analysis of the BATHS scale, confirmatory factor analysis (CFA) was performed to verify the compatibility of the items corresponding to each dimension and its diagram was shown in Figure 1. As seen in the diagram, since a significant correlation was observed between i1 and i2, and $i 7$ and i8 in the health dimension and between i4 and i5 in the persistence dimension, these correlations were added to the 
Table 1. Demographic properties and BATHS-T scores of participants $(N=273)$

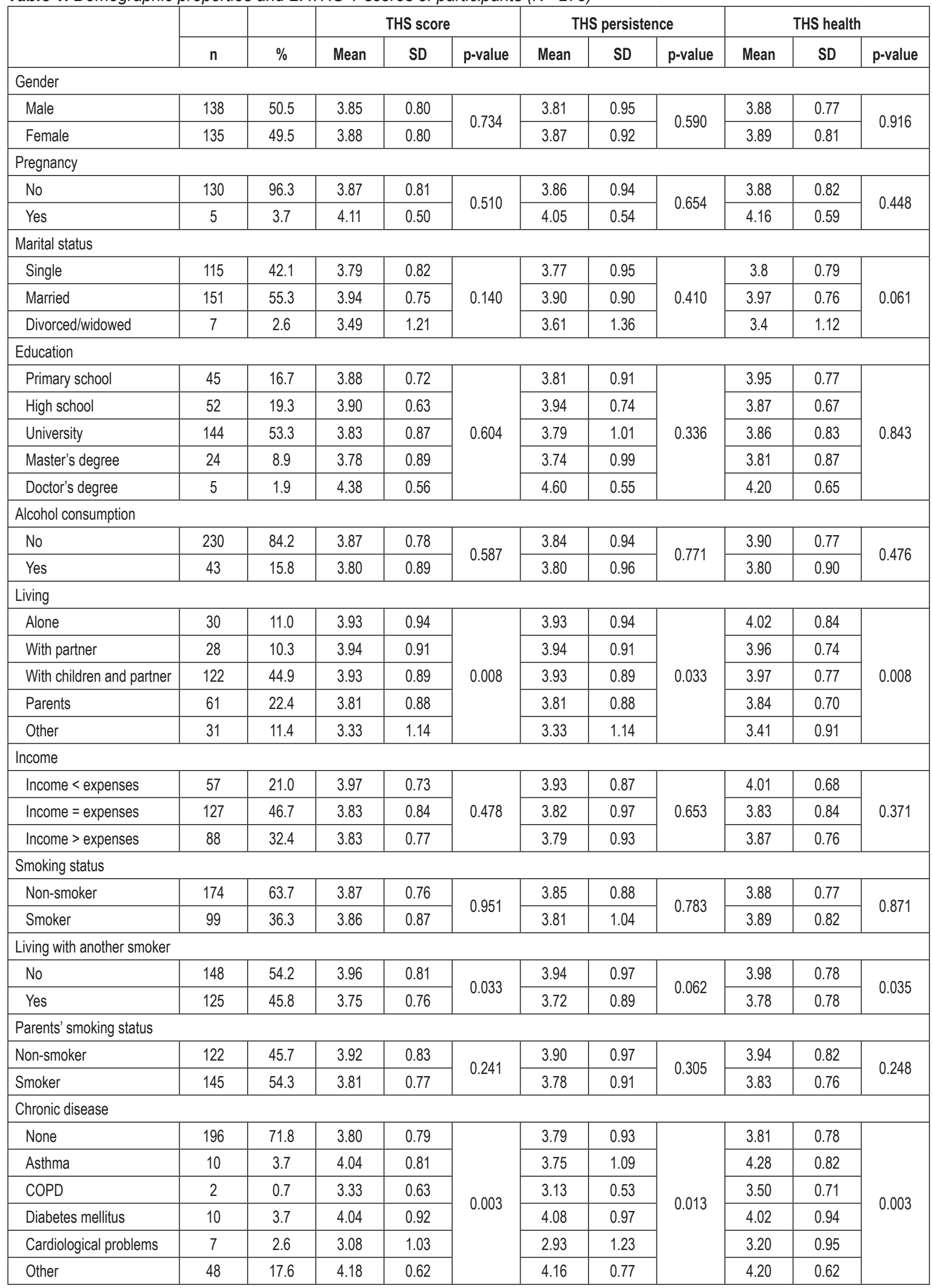




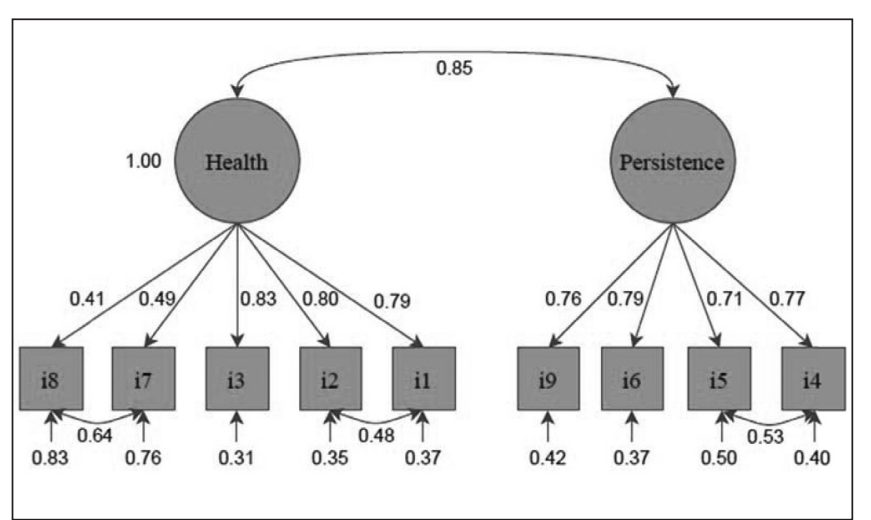

Fig. 1. Confirmatory factor analysis diagram of BATHS-T Scale.

model. Among the indices obtained according to CFA, the root mean square error of approximation (RMSEA) value was found as 0.123 , the standardized root mean square residual (SRMR) value was 0.076 , the comparative fit index (CFI) (24) value was 0.94, and the Tucker-Lewis index (TLI) (25) value was 0.90 . When these values were evaluated according to the compliance indices specified in the literature $(21,26,27)$, it was concluded that they are in the acceptable range.

\section{Criterion Validity}

Correlation between the overall BATHS scale and the health and persistence sub-dimensions for criterion validity is given in Table 2. The correlation between the overall BATHS scale and two sub-dimensions of the scale was $0.937(\mathrm{p}<0.001)$, and the correlation between the health and persistence sub-dimensions was $0.775(p<0.001)$. Since there was a statistically positive and highly significant relationship, the adapted Turkish THS scale was structurally compatible with the sub-dimensions.

\section{Reliability}

The reliability coefficients of the whole scale and its subdimensions in terms of internal consistency were calculated by the Cronbach's alpha method. The reliability value of the entire

Table 2. Correlations between subscales and total BATHS-T scores

\begin{tabular}{|c|c|c|}
\hline & THS & THS health \\
\hline THS health & $0.937^{* * *}$ & \\
\hline THS persistence & $0.937^{\star * \star}$ & $0.775^{\star * *}$ \\
\hline
\end{tabular}

scale was 0.90 . The reliability values of the health and persistence dimensions were 0.81 and 0.86 , respectively. Since the reliability values obtained were above the critical value of 0.70 , it was observed that the BATHS scale was reliable.

In addition to the Cronbach's alpha method, the reliability of the scale in terms of stability was examined with the test-retest method. According to the values given in Table 3, the test-retest correlation values between health and persistence dimensions were 0.745 and 0.960 , respectively, which were above 0.70 and had statistically positive and a high level of significant relationship $(\mathrm{p}<0.001)$. It can be said that the scale of BATHS is a highly reliable scale.

\section{Socio-demographic Variable Analysis}

In addition to the socio-demographic variables shown in Table 1 , the participants' age (ranged from 16 to 82 ) and the number of participanting children (ranged from 0 to 9 ) were also compared for the beliefs of the participants about third-hand smoke. When the standardized values of the dependent variable BATHS scale were examined, only three values $\left(\mathrm{z}_{1}=-3.413, \mathrm{z}_{2}=-3.413\right.$, and $\left.\mathrm{z}_{3}=-3.119\right)$ were determined as extreme values and were not included in the analysis. Therefore, analyses were carried out based on responses from 270 participants. For the t-test and ANOVA; kurtosis $(0.665)$ and skewness $(-0.881)$ values were suitable. Thus, normal distribution and homogeneity of variance assumptions were satisfied.

When the socio-demographic independent variables were compared, no statistically significant difference was observed between the participants' beliefs about third-hand cigarette smoke $(p>0.05)$ except for three items. According to responses to the item "Who do you live with at home?" statistically significant differences were observed between individuals sharing the home with different people $(\mathrm{F}=3.83 ; \mathrm{p}=0.008)$. This item had five different answer options (Table 1). ANOVA post-hoc multiple comparisons were implemented using Tukey HSD (Table 4). Individuals staying at home with others (mean $=3.33$ ) had statistically lower scores than individuals who lived alone $($ mean $=3.93)$, only with their spouse $($ mean $=3.94)$, spouse and children $($ mean $=3.93)$, and parents $($ mean $=3.81)$. According to responses to the item "Is there anyone else smoking at home rather than you?" the beliefs about the third-hand smoke of individuals who have no other smokers at home (mean=3.96) were found to be higher than those who have smokers other than them at home (mean $=3.75 ; \mathrm{t}=2.149 ; \mathrm{p}=0.033)$. "Do you have a chronic disease?" item has six different categories (Table 1), and individuals with other chronic diseases have higher beliefs about third-hand smoke than individuals with chronic heart disease and individuals without chronic diseases $(F=3.53$; $d f=5 ; p=0.003)$.

Table 3. Test-retest correlation coefficients

\begin{tabular}{|l|c|c|c|c|c|}
\hline & THS_1 & THS-H_1 & THS-P_1 & THS_2 & THS-H_2 \\
\hline THS-H_1 & $0.937^{* * *}$ & & & & \\
\hline THS-P_1 & $0.937^{* * *}$ & $0.757^{* * *}$ & & & \\
\hline THS_2 & $0.960^{* * *}$ & $0.900^{* * *}$ & $0.898^{* * *}$ & & \\
\hline THS-H_2 & $0.910^{* * *}$ & $0.952^{* * *}$ & $0.752^{* * *}$ & $0.944^{* * *}$ & \\
\hline THS-P_2 & $0.902^{* * *}$ & $0.745^{* * *}$ & $0.945^{* * *}$ & $0.942^{* * *}$ & $0.780^{* * *}$ \\
\hline
\end{tabular}


Table 4. Post-hoc tests (Tukey HSD)

\begin{tabular}{|c|c|c|c|c|c|c|}
\hline \multirow{2}{*}{ I } & \multirow{2}{*}{$J$} & \multirow{2}{*}{ Mean difference (I-J) } & \multirow{2}{*}{ Standard error } & \multirow{2}{*}{$\mathrm{p}$-value } & \multicolumn{2}{|c|}{$95 \%$ confidence interval } \\
\hline & & & & & Lower bound & Upper bound \\
\hline \multirow{4}{*}{0} & 1 & -0.0001 & 0.2578 & 1.000 & -0.7081 & 0.7079 \\
\hline & 2 & 0.0754 & 0.1999 & 0.996 & -0.4736 & 0.6245 \\
\hline & 3 & 0.1520 & 0.2188 & 0.958 & -0.4489 & 0.7528 \\
\hline & 4 & $0.7923^{*}$ & 0.2512 & 0.015 & 0.1023 & 1.4823 \\
\hline \multirow{4}{*}{1} & 0 & 0.0001 & 0.2578 & 1.000 & -0.7079 & 0.7081 \\
\hline & 2 & 0.0755 & 0.2056 & 0.996 & -0.4890 & 0.6401 \\
\hline & 3 & 0.1521 & 0.2239 & 0.961 & -0.4630 & 0.7671 \\
\hline & 4 & $0.7924^{*}$ & 0.2558 & 0.018 & 0.0900 & 1.4949 \\
\hline \multirow{4}{*}{2} & 0 & -0.0754 & 0.1999 & 0.996 & -0.6245 & 0.4736 \\
\hline & 1 & -0.0755 & 0.2056 & 0.996 & -0.6401 & 0.4890 \\
\hline & 3 & 0.0765 & 0.1538 & 0.988 & -0.3460 & 0.4990 \\
\hline & 4 & $0.7169^{*}$ & 0.1973 & 0.003 & 0.1749 & 1.2588 \\
\hline \multirow{4}{*}{3} & 0 & -0.1520 & 0.2188 & 0.958 & -0.7528 & 0.4489 \\
\hline & 1 & -0.1521 & 0.2239 & 0.961 & -0.7671 & 0.4630 \\
\hline & 2 & -0.0765 & 0.1538 & 0.988 & -0.4990 & 0.3460 \\
\hline & 4 & $0.6403^{*}$ & 0.2164 & 0.028 & 0.0461 & 1.2346 \\
\hline
\end{tabular}

*Mean difference is significant at the 0.05 level.

\section{DISCUSSION}

Turkey has achieved significant success in controlling tobacco use within the last 20 years. However, there are still some challenging areas. Third-hand smoke is not a new problem in public health, but it is mostly ignored in Turkey. Effective control strategies are needed for THS exposure (28).

In particular, interfering with beliefs about THS can be beneficial in reducing THS and second-hand smoke exposure. As a result, using a valid and reliable belief scale related to THS is critical in evaluating these intervention efforts (20). In the present study, our data showed that the Turkish version of the BATHS is a valid and reliable scale to use for Turkish population.

Original scale had overall excellent reliability (Cronbach's alpha $=0.91$ ) and sub-scales had strong reliability (Cronbach's alpha $=0.88$ for both factors) (14). Turkish version had very similar total reliability (Cronbach's alpha $=0.90$ ) besides powerful reliability in the sub-scales (Cronbach's alpha $=0.81$ for THS persistence and 0.86 for THS health sub-dimensions).

There are many articles on beliefs about third-hand smoke but only one has used the same scale and translated it into Bengali (29). They found persistence in low subscale reliability (Cronbach's alpha $=0.624$ ) and they dropped one of the four items to improve reliability. Health subscale reliability was also lower than the original scale and Turkish version (Cronbach's alpha $=$ 0.742). This difference may be due to the intercultural differences and/or problems with translation, and they did not mention the validity analysis.

In our study, the obtained coefficient of stability was 0.960 , which supports that the internal validity of the Turkish version of BATHS is high. In addition to the original BATHS scale supported by construct validity (20), construct validity of Turkish
BATHS was further investigated by factor analysis. The latest version of the scale, including scoring instructions, is available in Appendix 1 (20).

Socio-demographic factors such as gender, marital status, and education did not affect total BATHS score in our study, whereas these parameters had an impact on English BATHS scores. It was interesting that the smoking status of the participants did not have any effects on beliefs about THS in the present study unlike in Haardörfer et al. study (20). An explanation for this difference could be due to $2 / 3$ non-smokers in our study compared to $2 / 3$ smokers in their study. Current or former smokers also reported lower levels of beliefs in the study made in Bangladesh (29).

There are limitations of the present study. One is the lack of generalizability of the results as the sample was only from a Southeastern city of Turkey. Therefore, the results cannot be extended to entire country because there are socioeconomic and cultural differences among different cities of Turkey. Besides, test-retest reliability was used but respondents' previous experiences in the first testing could have influenced responses in the second testing.

\section{CONCLUSIONS}

This study confirms that the Turkish version of the BATHS is valid and reliable to administer to participants in Turkey. Usage of this scale will enable further studies and will increase the awareness about THS. People are expected to follow the rules for prevention of THS more strictly, when they are aware of the danger caused by it.

\section{Conflicts of Interests}

None declared 


\section{Authors' Contribution}

D.Ç. - design of the work, drafting the work, writing the manuscript; N.K.T. - data collection, interpretation of data for the work; R.T. - design of the work, statistical analysis, writing the manuscript; F.G.C. - design of the work, drafting the work. All authors have approved the final version to be published.

\section{REFERENCES}

1. Ferrante G, Simoni M, Cibella F, Ferrara F, Liotta G, Malizia V, et al Third-hand smoke exposure and health hazards in children. Monaldi Arch Chest Dis. 2013;79(1):38-43.

2. Martins-Green M, Adhami N, Frankos M, Valdez M, Goodwin B, Lyubovitsky J, et al. Cigarette smoke toxins deposited on surfaces: implications for human health. PLoS One. 2014;9(1):e86391. doi: 10.1371/journal. pone.0086391.

3. Moritsugu KP. The 2006 Report of the Surgeon General: the health consequences of involuntary exposure to tobacco smoke. Am J Prev Med. 2007;32(6):542-3.

4. Bahl V, Jacob P 3rd, Havel C, Schick SF, Talbot P. Thirdhand cigarette smoke: factors affecting exposure and remediation. PLoS One. 2014;9(10):e108258. doi: 10.1371/journal.pone.0108258.

5. Winickoff JP, Friebely J, Tanski SE, Sherrod C, Matt GE, Hovell MF, et al. Beliefs about the health effects of "thirdhand" smoke and home smoking bans. Pediatrics. 2009;123(1):e74-9.

6. Rabin RC. A new cigarette hazard: 'third-hand smoke' [Internet]. The New York Times Company; 2009 [cited 2019 Dec 27]. Available from: https://www.nytimes.com/2009/01/03/health/research/03smoke.html.

7. Szabo L. Babies may absorb smoke residue in home [Internet]. USA Today; 2006 [cited 2019 Dec 27]. Available from: https://usatoday30. usatoday.com/news/health/2006-08-06-thirdhand-smoke-usat_x.htm.

8. Xu B, Chen M, Yao M, Ji X, Mao Z, Tang W, et al. Metabolomics reveals metabolic changes in male reproductive cells exposed to thirdhand smoke. Sci Rep. 2015;5:15512. doi: 10.1038/srep15512.

9. Matt GE, Quintana PJ, Destaillats H, Gundel LA, Sleiman M, Singer $\mathrm{BC}$, et el. Thirdhand tobacco smoke: emerging evidence and arguments for a multidisciplinary research agenda. Environ Health Perspect. 2011;119(9):1218-26.

10. Sleiman M, Gundel LA, Pankow JF, Jacob P 3rd, Singer BC, Destaillats $\mathrm{H}$. Formation of carcinogens indoors by surface-mediated reactions of nicotine with nitrous acid, leading to potential thirdhand smoke hazards. Proc Natl Acad Sci U S A. 2010;107(15):6576-81.

11. Rehan VK, Sakurai R, Torday JS. Thirdhand smoke: a new dimension to the effects of cigarette smoke on the developing lung. Am J Physiol Lung Cell Mol Physiol. 2011;301(1):L1-8.

12. Yolton K, Dietrich K, Auinger P, Lanphear BP, Hornung R. Exposure to environmental tobacco smoke and cognitive abilities among U.S. children and adolescents. Environ Health Perspect. 2005;113(1):98-103.

13. Thomas JL, Guo H, Carmella SG, Balbo S, Han S, Davis A, et al. Metabolites of a tobacco-specific lung carcinogen in children exposed to secondhand or thirdhand tobacco smoke in their homes. Cancer Epidemiol Biomarkers Prev. 2011;20(6):1213-21.

14. Alberg AJ, Shopland DR, Cummings KM. The 2014 Surgeon General's report: commemorating the 50th Anniversary of the 1964 Report of the Advisory Committee to the US Surgeon General and updating the evidence on the health consequences of cigarette smoking. Am J Epidemiol 2014;179(4):403-12.

15. Becquemin MH, Bertholon JF, Bentayeb M, Attoui M, Ledur D, Roy F, et al. Third-hand smoking: indoor measurements of concentration and sizes of cigarette smoke particles after resuspension. Tob Control. 2010;19(4):347-8.

16. Matt GE, Quintana PJ, Fortmann AL, Zakarian JM, Galaviz VE, Chatfield DA, et al. Thirdhand smoke and exposure in California hotels: nonsmoking rooms fail to protect non-smoking hotel guests from tobacco smoke exposure. Tob Control. 2014;23(3):264-72.

17. Escoffery C, Bundy L, Carvalho M, Yembra D, Haardörfer R, Berg C, et al. Third-hand smoke as a potential intervention message for promoting smoke-free homes in low-income communities. Health Educ Res. 2013;28(5):923-30.

18. Drehmer JE, Ossip DJ, Nabi-Burza E, Rigotti NA, Hipple B, Woo H, et al. Thirdhand smoke beliefs of parents. Pediatrics. 2014;133(4):e850-6.

19. Kegler MC, Bundy L, Haardörfer R, Escoffery C, Berg C, Yembra D, et al. A minimal intervention to promote smoke-free homes among 2-1-1 callers: a randomized controlled trial. Am J Public Health. 2015;105(3):530-7.

20. Haardörfer R, Berg CJ, Escoffery C, Bundy ŁT, Hovell M, Kegler MC. Development of a scale assessing Beliefs About ThirdHand Smoke (BATHS). Tob Induc Dis. 2017;15:4. doi: 10.1186/s12971-017-0112-4.

21. Kline RB. Principles and practice of structural equation modeling. 4th ed. New York: Guilford Press; 2016.

22. Nunnally JC. Psychometric theory. 2nd ed. New York: McGraw-Hill; 1978.

23. Muthén LK, Muthén BO. Mplus user's guide: statistical analysis with latent variables. 7th ed. [Internet]. Los Angeles: Muthén \& Muthén; 2015 [cited $2021 \mathrm{Feb} 7]$. Available from: https://www.statmodel.com/ download/usersguide/MplusUserGuideVer_7.pdf.

24. Bentler PM. Comparative fit indexes in structural models. Psychol Bull. 1990 Mar;107(2):238-46.

25. Tucker LR, Lewis C. A reliability coefficient for maximum likelihood factor analysis. Psychometrika. 1973 Mar;38(1):1-10.

26. Bentler PM. EQS 6 Structural Equations Program Manual. Encino: Multivariate Software; 2006.

27. Browne MW, Cudeck R. Alternative ways of assessing model fit. Sociol Methods Res. 1992;21(2):230-58.

28. Bilir N. Successes and challenges in tobacco control-Turkish experience of 20 years. Eurasian J Pulmonol. 2017;19(3):119-23.

29. Kamimura A, Ahmmad Z, Pye M, Gull B. Peer smoking and smokingrelated beliefs among college students in Bangladesh. J Prev Med Public Health. 2018;51(1):51-8. 